\title{
Damaged ligaments at the craniocervical junction presenting as an extradural tumour: a differential diagnosis in the elderly
}

\author{
H A Crockard, P Sett, J F Geddes, J M Stevens, B E Kendall, J A S Pringle
}

\begin{abstract}
An extradural mass at the craniocervical junction causing progressive neurological disability in five elderly patients is described. The lesion, which might be confused with a meningioma or other tumour, is composed of amorphous degenerate fibrocartilaginous material and could be due to degeneration of the ligaments responsible for atlanto-axial stability. Recognition of the condition early is important as the patient's clinical condition will deteriorate without decompression. Anterior transoral removal is relatively simple, unlike surgery for tumours in the area, and will not destabilise the craniovertebral junction. It is likely that a proportion of these lesions are undetected, misdiagnosed or untreated to the detriment of the patient.
\end{abstract}

Tumours at the craniocervical junction are uncommon $^{1}$ and difficult to diagnose clinically. ${ }^{1}$ Symptoms and signs often result in a presumptive diagnosis of multiple sclerosis in the young and brain stem vascular insufficiency in the elderly. ${ }^{1-3}$ The tumours most often encountered are usually neoplasms; meningiomas when bone erosion is absent, and neurofibromas, chordomas and metastases when bone erosion or destruction is present. ${ }^{4-6}$ Many non-neoplastic mass lesions also have been reported. Recently, relatively invasive tests such as myelography and computed myelography were necessary for diagnosis, but since most of these lesions occur more commonly in the elderly such tests often were avoided or at least delayed. MRI has the advantage of being non-invasive, and its increasing availability is leading to more patients being investigated when symptoms are mild or equivocal. One outcome has been the realisation that non-tumoural conditions are more common than was formerly recognised, ${ }^{5-10}$ and at least one new pathological entity has been described recently. ${ }^{8}$ We describe five elderly patients, each with a noninflammatory, acellular mass, histologically resembling material from a degenerate intervertebral disc, posterior to the odontoid which was severely compressing the upper spinal cord.

Material and methods

All the patients had had plain radiographs of the craniocervical junction. Three had MRI studies of the area and two had CT myelography. In four the radiological diagnosis was meningioma, and in one the possibility of ossifying posterior longitudinal ligament was raised. In four patients a transoral approach was used to remove the retrodental mass with minimal bone resection so as not to compromise atlanto-axial stability.

Post operatively all cases were reassessed for common clinical and radiological features (table), and all pathological material was examined with particular attention to bone and connective tissue stains.

\section{Case histories}

Case 1

A 67 year old woman presented initially with pain in her left hand and a "bursting feeling" which was diagnosed as median nerve compression and which did not respond to a carpal tunnel decompression. The condition progressed to numbness and weakness in both upper limbs and a fluctuating level of spastic quadriparesis two months before her final presentation. Several weeks before her referral she had transient episodes of respiratory difficulty, diminished bladder sensation and a weak voice.

On examination there was a depressed gag reflex, fluctuating weakness in upper and lower limbs, wasting of the small muscles of both hands, hyperreflexia in the arms and legs, bilateral extensor plantars. There was a loss of pinprick sensation up to the second cervical vertebra but joint position sensation was intact. Respiratory function and sleep studies demonstrated an $\mathrm{FEV}_{1}$ of $1.04 . \mathrm{FEV}_{1} / \mathrm{FVC}$ of 1 excluded an obstructive airways disease. The tests pointed to a neurological cause for her respiratory depression.

Plain radiographs showed some osteoarthrosis in the atlanto-axial joints but no erosions or subluxation.

The MRI revealed a smooth extradural mass behind the odontoid and an unusually posterior location of the neural axis which otherwise did not appear compressed. Axial images from a subsequent computed myelogram (fig 1a) showed that it consisted of two lateral lobulations which were indenting the antero-lateral surfaces of the spinal cord, and causing considerable compressive deformity.

She deteriorated rapidly with a bulbar palsy and an aspiration pneumonitis and an urgent transoral procedure was carried out. The arch of the atlas and the odontoid peg were normal. 


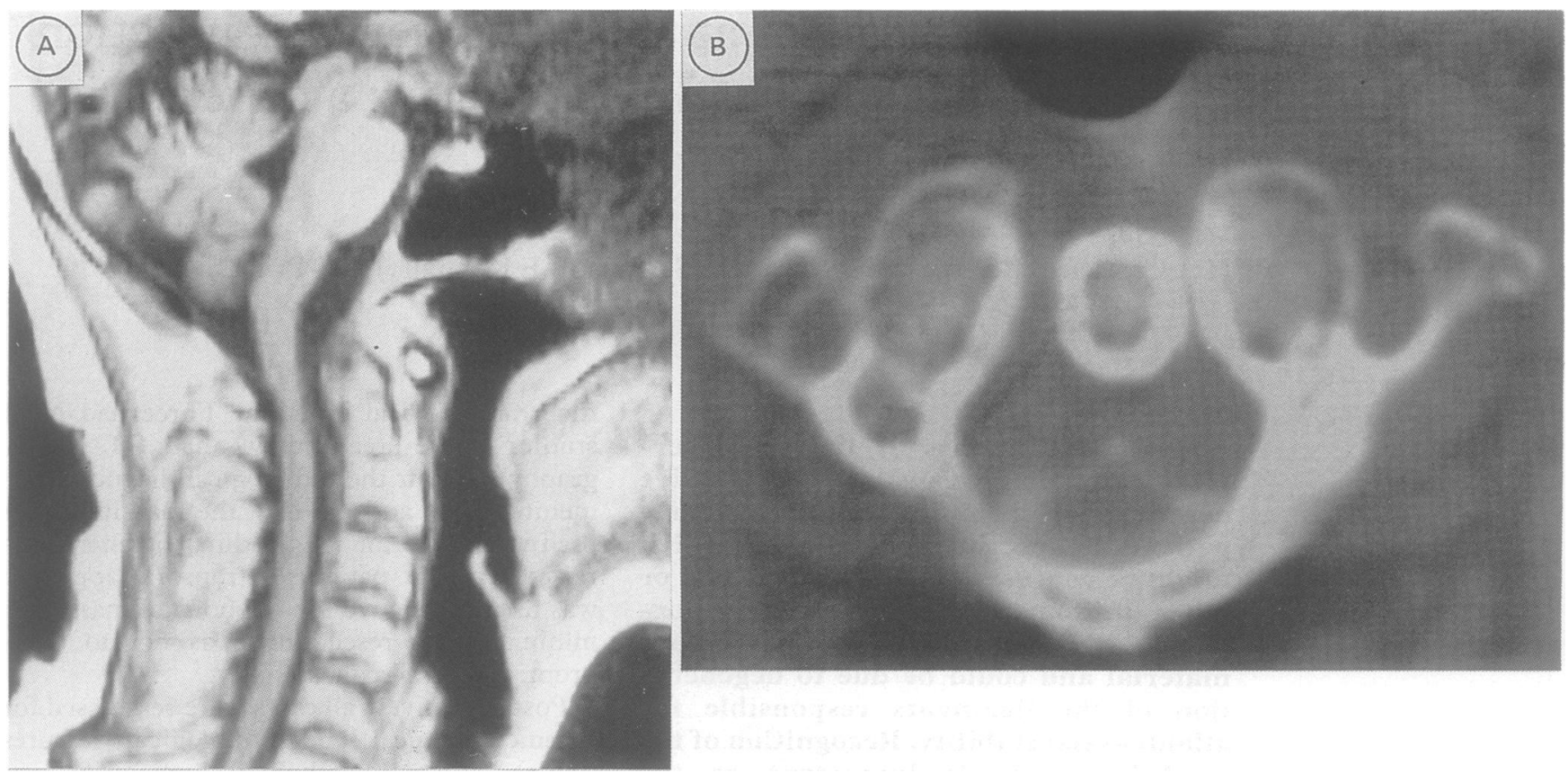

Figure 1a) Sagittal MRI of case 1, T1 weighted spin echo image (TR 500, TE 26 at 0.26 Tesla). In the mid sagittal plane the retrodental mass presents a smoothly convex posterior contour, whose compressive effect on the spinal cord is manifest only by the abnormally posterior location of the neural axis as it traverses the craniocervical junction. b) Axial image of the computed myelogram on case 1, through C1. The lateral lobulations of the retrodental mass are shown, and the anterolateral concavities in the spinal cord from the compression they are causing.

The "tumour" was firm, yellowish, amorphous material, entirely extradural without capsule but very adherent to the cruciate and posterior longitudinal ligaments. A complete excision was possible and a bone graft inserted.

Despite the decompression, the bronchopneumonia progressed and caused her death. A necropsy confirmed the severe bronchopneumonia with a right lung abscess.

\section{Case 2}

This extremely fit 83 year old man complained of a seven month history of paraesthesia in the left hand which progressed to numbness in the left upper and lower limb. He had difficulty in doing buttons and holding objects in the affected hand and there was a progressive left sided weakness. He had some neck pain and particularly pain in the $\mathrm{C} 2$ distribution for about the same time but denied any trauma.

Figure 2 Sagittal MRI of case 2, T1 weighted spin echo image (TR 500, TE 30 at 0.5 Tesla). The large posteriorly convex retrodental mass is shown causing marked midsagittal compression of the spinal cord. (The nature and significance of the dark band across the superior part of the odontoid is uncertain; it was not visible on plain radiographs or computed myelography). Tissue of apparently similar texture and signal is visible within and below the atlantodental interval.

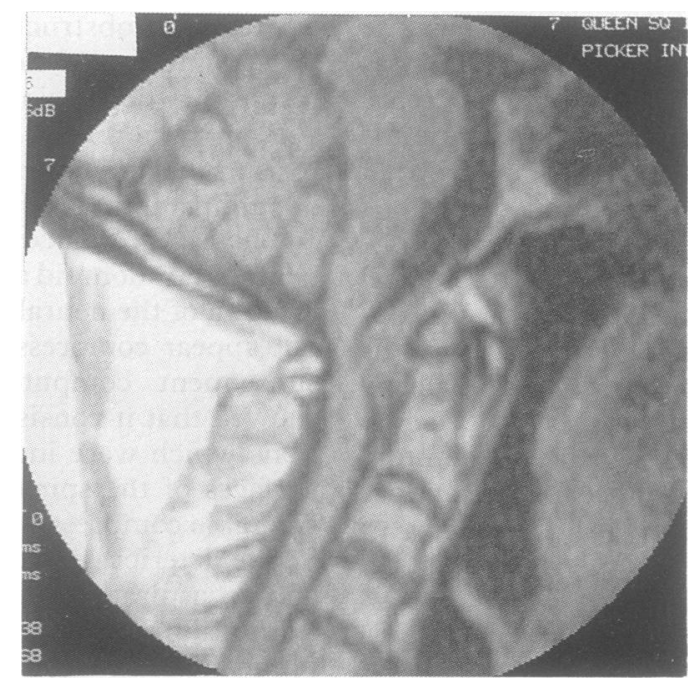

Plain radiographs of the cervical spine revealed marked degenerative changes with anterior and posterior osteophytes in the mid and lower cervical region. There was no atlanto-axial subluxation or erosion of the first two vertebrae, but osteoarthritic changes were present at $\mathrm{C} 1 / \mathrm{C} 2$. MRI showed moderate mid cervical spondylotic cord compression, and an extensive mass at the atlanto-axial level anterior to the cord (fig 2).

A presumptive diagnosis of meningioma was made and he was observed for a period of six months. The clinical condition deteriorated to the point where he was no longer able to walk around freely by himself without falling and a repeat MRI scan revealed a slight increase in size of the anterior extradural mass, and suggested, in addition, focal oedema in the cord at the site of maximum compression. In view of the deterioration, a transoral approach was carried out to the mass, with excision of some normal bone from the odontoid, which was not fractured. Yellowish amorphous material extruded from between the odontoid and the arch of $\mathrm{Cl}$ when the anterior capsule had been incised, and similar tissue was removed from behind the odontoid by suction and rongeurs, and a good decompression of the dura was obtained with minimal bone removal.

Postoperatively the patient recovered from the procedure and is now fully ambulant without a hemiparesis.

Case 3

A 79 year old man presented with a history of a progressive spastic quadriparesis of three months' duration. Over the two weeks before admission, he had developed intense extensor spasms in the lower limbs. More recently, he had had some difficulty with swallowing and had experienced disturbing nightmares. 
Table Radiological features of the "extradural tumours"

\begin{tabular}{|c|c|c|c|c|c|c|c|c|c|c|}
\hline \multirow[b]{2}{*}{ Patient } & \multirow{2}{*}{$\begin{array}{l}\text { Type of } \\
\text { study }\end{array}$} & \multirow{2}{*}{$\begin{array}{l}\text { Atlanto-axial } \\
\text { subluxation }\end{array}$} & \multirow[b]{2}{*}{ Erosions } & \multirow{2}{*}{$\begin{array}{l}\text { Subaxial } \\
\text { changes }\end{array}$} & \multirow{2}{*}{$\begin{array}{l}\text { Cord } \\
\text { compression }\end{array}$} & \multicolumn{5}{|l|}{ The mass } \\
\hline & & & & & & Site (max) & Extent & Calcification & Lobulation & NMR signal \\
\hline $\begin{array}{l}1(\mathbf{F}) \\
2(\mathbf{M}) \\
3(\mathbf{M}) \\
4(\mathbf{M}) \\
5(\mathbf{F})\end{array}$ & $\begin{array}{l}\text { CT MRI } \\
\text { MRI } \\
\text { CTM } \\
\text { CTM } \\
\text { CT MRI }\end{array}$ & $\begin{array}{l}\text { Mild anterior } \\
\text { Nil } \\
\text { Nil } \\
\text { Nil } \\
\text { Nil }\end{array}$ & $\begin{array}{l}\text { Nil } \\
\text { Nil } \\
\text { Yes } \\
\text { Nil } \\
\text { Yes }\end{array}$ & $\begin{array}{l}\text { Mild spondylosis } \\
\text { Nil } \\
\text { Severe spondylosis } \\
\text { Mild spondylosis } \\
\text { Severe spondylosis }\end{array}$ & $\begin{array}{l}++ \\
+++ \\
++ \\
++ \\
+++\end{array}$ & $\begin{array}{l}\text { Atlas ring } \\
\text { Atlas ring } \\
\text { Atlas ring } \\
\text { Atlas ring } \\
\text { Atlas ring }\end{array}$ & $\begin{array}{l}\text { Basion to base of } \mathrm{C} 2 \\
\text { Basion to base of } \mathrm{C} 2 \\
\text { Basion to base of } \mathrm{C} 2 \\
\text { Basion to base of } \mathrm{C} 2 \\
\text { Basion to base of } \mathrm{C} 2\end{array}$ & $\begin{array}{l}\text { Nil } \\
\text { Nil } \\
\text { Yes } \\
\text { Yes } \\
\text { Yes }\end{array}$ & $\begin{array}{l}\text { Yes } \\
\text { Nil } \\
\text { Yes } \\
\text { Nil } \\
\text { Yes }\end{array}$ & $\begin{array}{l}\text { Similar to brain } \\
\text { Similar to brain } \\
= \\
\overline{\text { Low }}\end{array}$ \\
\hline
\end{tabular}

The features in common:

1) Site of maximal mass $(\mathrm{C} 1)$

2) Extent (basion to base of $\mathrm{C} 2$ )

3) Some evidence of spondylosis in cervical spine (severe in two; virtually absent in one)

4) Absence of atlanto-axial instability (only one had mild widening of atlanto-dental interval)

5) Moderate or severe cord compression

Variable features:

1) Corticated erosions at ligament attachment - transverse ligament and atlas - two

2) Lobular mass (not smoothly convex) $2 / 5$-posterior surface of dens-two (both types in D.B.)

3) Calcification 2/5

4) NMR sigal on T1 and T2 weighted images (three cases) low (1); brain-like (2).

Two years before, he had presented with a spastic quadriparesis and, at that stage, was found to have significant cervical spondylosis with cord compression at $\mathrm{C} 3$ and C4. For this he had an anterior microsurgical spinal decompression with bone grafting which had resulted in an improvement of his condition. He had remained well until his recent deterioration.

His gemeral physical condition was extremely poor. He was in left ventricular failure, hypertensive with cardiac arrhythmias.

Plain radiographs excluded atlanto-axial subluxation. There were marked spondylotic changes and evidence of osteoarthrosis at $\mathrm{Cl} /$ C2. The site of the previous Cloward procedure revealed a firm union.

A CT myelogram confirmed that there was no further compression at the previous level. What was considered to be early ossifying posterior longitudinal ligament noted on the myelogram two years before was now larger and was compressing the cord at the craniocervical junction.

A transoral procedure was carried out and this revealed a normal bone of the odontoid peg and arch of $\mathrm{Cl}$. Degenerative amorphous material with occasional calcified areas was removed and a good decompression effected in this way.

Postoperatively, after temporary cardiovascular problems, he made a good recovery with improvement in his spastic quadriparesis.

\section{Case 4}

A 78 year old man presented with a two year history of progressive paraesthesia, weakness and clumsiness of both hands which caused his writing to deteriorate. Three months before admission he had noticed a deterioration in his gait. More recently he complained of shooting pains down the left side.

On examination he was confined to a wheelchair with spastic quadriparesis with obvious increase in tone and reflexes and bilateral extensor plantars. He was unable to support himself. Joint position was absent in all four limbs. He had no sphincter problems.

Computed myelotomography showed a smooth extradural mass behind the odontoid which was not calcified and lacked the lobula- tion shown in case 1 . There was no evidence of atlanto-axial instability.

A transoral removal of the extradural mass was carried out. Most of the fibrous avascular lesion was removed. Histologically, the lesion consisted of amorphous, acellular material containing fibrous tissue and cartitage.

Plain radiographs of the craniocervical region showed no instability postoperatively and initially he progressed very well following the operation. One week from the day of operation his condition deteriorated. His condition was too poor for further surgical management to be considered and he finally died of bronchopneumonia.

\section{Case 5}

An 82 year old woman presented with a long history of neck pain and evidence of cervical spondylosis, and more recently a ten month history of progressive weakness of the arms and legs. Her hand function was particularly affected and there was obvious wasting of the small muscles of the hand. She had become increasingly disabled and unable to look after herself. Surgery has been deferred in view of her age.

Plain radiographs of the craniocervical junction excluded any instability. MRI showed a large irregular retrodental extradural intraspinal mass with marked spinal cord compression. Plain CT showed that the mass had areas of calcium (fig 3a, b and c).

\section{Discussion}

All the patients reported in this series were elderly, with a relatively short history of neurological disability. In none was there any history of relevant antecedent trauma. Four of the five patients had difficulty using their hands, and spastic tetraparesis was present at the time of their referral for neurosurgical management. Two had signs of bulbar palsy, including respiratory insufficiency in one. Clinical features were progressive, and it was likely that without operative intervention the patients would have died. Since the cause of the compression was not neoplastic, and amenable to surgical excision, the recognition of this new 
Figure 3a) Sagittal MRI of the cervical spine in case 5, $T 1$ weighted spin echo image (TR 500, TE 26, 0.26 Tesla). A large irregular low signal mass is shown behind the odontoid compressing the spinal cord. It appears to be surrounded by epidural fat. The cervical intervetebral discs show marked resorptive changes. b) Sagittal MRI in case 5 , T2 weighted spin echo image (TR 1800, TE 120, 0.26 Tesla). The

retrodental mass is shown to consist of materials of different signal intensity. The dark areas presumably represent acellular fibrous tissue and calcification, but the nature of brighter areas is less certain. Histological confirmation was not obtained in this case. $c$ ) Axial CT image through the atlas, mainly

hyperdense mass is shown behind the odontoid which contains calcified or ossified debris. At the sites of attachment of the transverse ligament there are deep, but well corticated erosions of the atlas, and there is minimal erosion of the posterior surface of the odontoid.
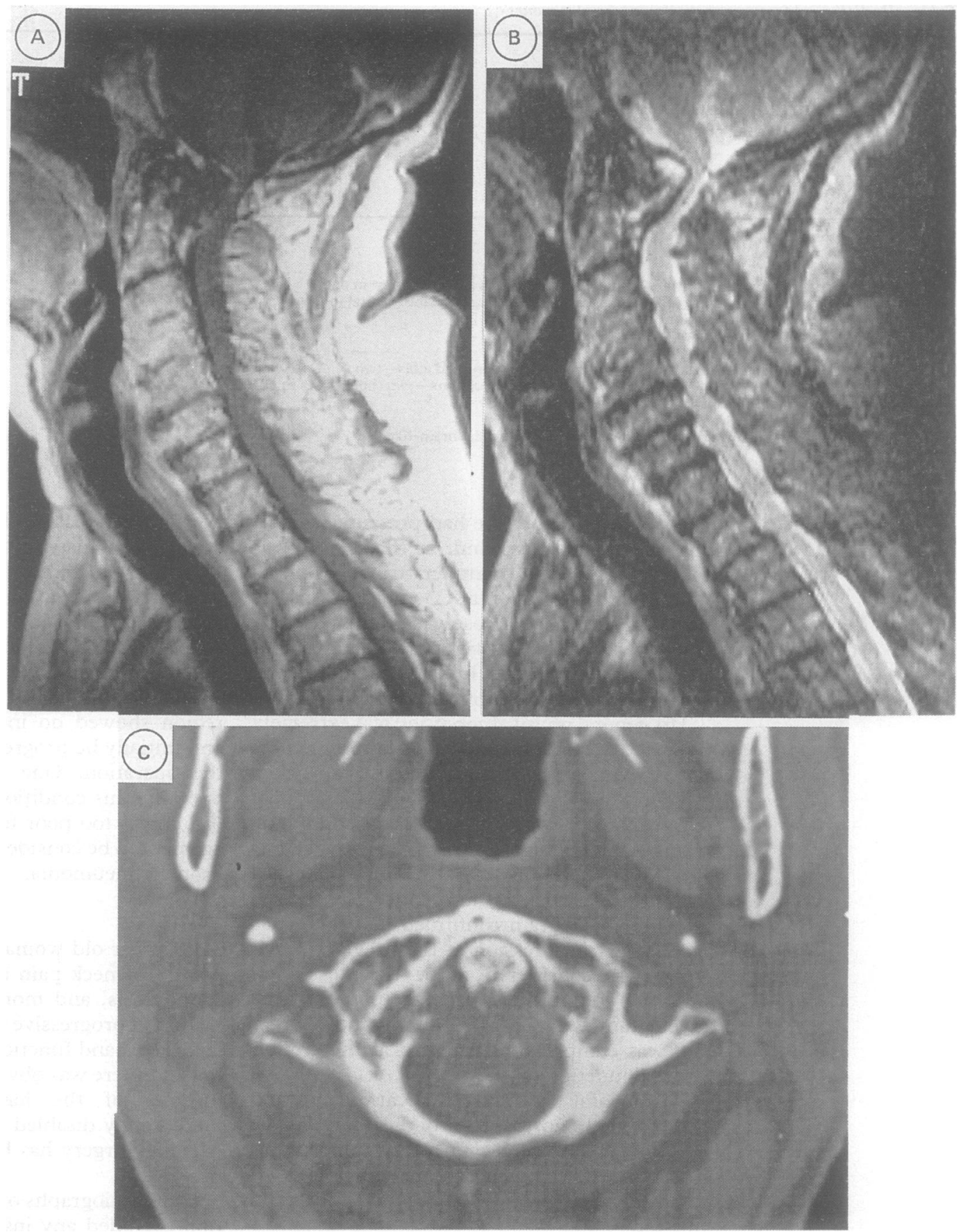

pathological entity is of importance.

Many types of non-neoplastic mass have been described at or near the craniocervical junction. These have included rheumatoid arthritis, ${ }^{24}$ hypertrophy of the ligamentum flavum, ${ }^{18}$ synovial cyst, ${ }^{19}$ ossifying posterior longitudinal ligament, ${ }^{7}$ elastofibroma, ${ }^{20}$ tophaceous gout, ${ }^{22}$ calcium pyrophosphate dihydrate deposition disease, ${ }^{23}$ hypertrophic non-union of odontoid fracture, ${ }^{25}$ and posttraumatic peri-odontal cicatrix. ${ }^{26}$ Also Sze et $a l^{8}$ recently described several elderly patients with retro-odontoid "pseudotumours", osteoarthritic changes in the adjacent joints, and chronic atlanto-axial subluxation. Histological features differed a little from the cases reported here in that inflammatory cells were present and the process was attributed to a reactive soft tissue response to the chronic subluxation.
The peri-odontoid "pseudotumours" in our cases consisted of amorphous yellowish material, sometimes friable, sometimes gritty in texture. The histological appearance in each was identical, and consisted of degenerate ligament, fibrocartilage, much of which was acellular and necrotic, and fibrin. No inflammatory cells were present. In some areas fibrovascular ingrowths were seen. Fragments of ligamentous insertions were also included (fig 4 ), and the ligaments appeared fibrillated and disintegrating although the underlying bone was normal. There was also evidence of early joint damage, with amorphous calcified debris and small pieces of bone incorporated in the synovial fragments. However, this was not a synovial disease like pigmented villonodular synovitis and synovial chondromatosis ${ }^{21}$ and no calcium pyrophosphate dihydrate or uric acid crystals were seen. In fact, the material closely 
Figure 4 Material taken from case 2 at operation. The ligament is seen to be degenerate and fibrillated (arrows) a short distance from its insertion $(\times 120)$.

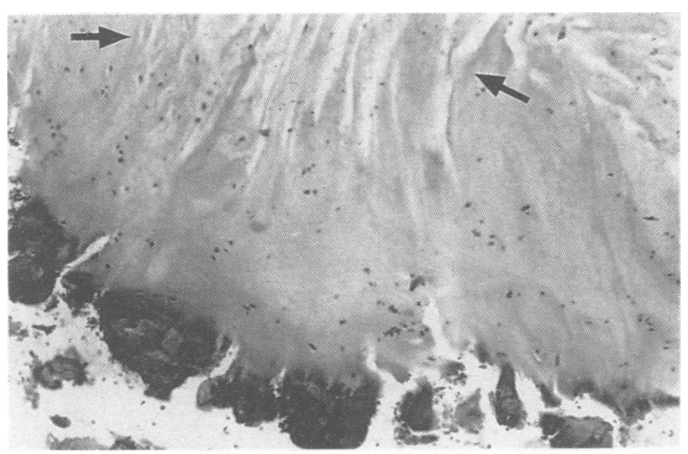

resembled the fragments commonly obtained from lumbar discectomy. Identical changes, including fibrovascular ingrowths and fibrocartilaginous metaplasia, have been seen in supraspinous and interspinous ligaments in patients with resorptive intervertebral disc disease, ${ }^{12}$ and some workers have gone so far as attributing the degenerative disc disease to local damage in the paraspinal ligaments. ${ }^{13}$ Similar ligamentous abnormalities have been found in the rotator cuff at the shoulder joint ${ }^{14}$ and patellar ligaments at the knee. ${ }^{15}$ The pathology of hypertrophy of the posterior longitudinal ligament, sometimes associated with a myelopathy of compressive aetiology, is also similar. ${ }^{1617}$ In our opinion these elderly patients with degenerative disease of the cervical spine develop a partial tear of the posterior longitudinal ligament, or in our cases, probably of the transverse ligament, and a cycle of attempted repair and mass formation ensues. It may begin as a partial ligamentous avulsion with retraction of the ligament and oedema; fibrocartilaginous metaplasia and fibrovascular ingrowth represent attempts at repair, and a vicious cycle starts leading to production of a progressively enlarging mass.

Pre-operative diagnosis depends upon imaging, especially MRI which is less invasive than myelography and post-myelography CT. In all operated cases in which MRI had been performed, the mass was smooth and yielded an homogeneous "brain" like signal of T1 weighted spin echo images, identical to the cases of Sze et al. ${ }^{8}$ This appearance is similar to meningioma at the craniovertebral junction, ${ }^{11}$ although usually these are somewhat eccentric anterior intraspinal masses reflecting a lateralised origin. ${ }^{24}$ Peri-odontal "pseudotumours" have been lobulated, with symmetrical lateralised lobulations (fig $1 \mathrm{~b}$ ), or smooth midline lesions. ${ }^{8}$ Calcification may be present, as in two of our cases, and in one it was sufficient to suggest ossification of the posterior longitudinal ligament. Atlanto-axial instability was not demonstrated in any of our cases, but all showed moderate or severe cervical spondylosis. Erosions at the site of the transverse ligament attachment were shown in one of the operated cases, and also in case 5 , and these are considered a non-specific feature presumably related to enthesial damage and attempted repair.

We believe that in the appropriate clinical setting, that is, of an elderly patient with cervical spondylosis on plain radiographs, and a history of a progressive high cervical myelopathy, in whom MRI or computed myelography shows a symmetrical rather than eccentric peri-odontal mass compressing the neural axis, the diagnosis of reparative "pseudotumour" becomes probable. Surgical removal via a transoral approach has been relatively straightforward, was usually well tolerated, and removal of minimal bone should prevent the operation causing instability.

We are grateful to Mr R Maurice-Williams and Dr A Valentine, The Royal Free Hospital, London and Dr D Spitzer, New York for permission to include cases 4 and 5 . We also thank M Green for the preparation of this paper.

The study was supported jointly by the Sir Jules Thorn Charitable Trust and His Highness the Aga Khan.

P Sett was the Thorn Research Fellow.

1 Editorial: Missed foramen magnum tumours. The Lancet 1973;ii: 1482 .

2 Blom S, Ekbom KA. Early clinical signs of meningiomas of the foramen magnum. $J$ Neurosurg 1962;19:661-4.

3 Symmonds CP, Meadows SP. Compression of the spinal cord in the neighbourhood of the foramen magnum. Brain 1967;60:52-84.

4 Guidetti B, Spallone A. Benign extramedullary tumours of the foramen magnum. Surg Neurol 1980;13:9-17.

5 Meyer FB, Ebersold MJ, Reese DF. Benign tumours of the foramen magnum. $J$ Neurosurg 1984;61:136-42.

6 Harkey HL, Crockard HA. Spinal meningiomas: clinical features. In: Al Mefty O, ed. Meningiomas. New York: Raven Press, 1991:563-71.

7 Harsh IV GR, Sypert GW, Weinstein PR, Ross DA, Wilson $\mathrm{CD}$. Cervical spine stenosis secondary to ossification of the CD. Cervical spine stenosis secondary to ossification of the
posterior longitudinal ligament. J Neurosurg 1987;67: posterio

8 Sze G, Brant-Zawadzki MN, Wilson CB, Norman D, Newton TH. Pseudotumour of the craniovertebral junction associated with chronic subluxation: MR imaging studies. Radiology 1986;161:391-4

9 Lee BCP, Deck MDF, Kneeland JB, Cahill PT. MR imaging of the craniovertebral junction. AJNR 1985;6:209-13.

10 Lufkin R, Vineula F, Benston JR, Dion JE. Magnetic resonance imaging of the craniovertebral junction. Comput Med Imaging Graph 1988:12(5):281-92.

11 Takemoto $\mathrm{K}$, Matsumura $\mathrm{Y}$, Hashimoto $\mathrm{H}$, et al. MR imaging of intraspinal tumour-capability in histological differentiation and compartmentalisation of extramedullary tumours. Neuroradiol 1988;30:303-9.

12 Yahia H, Drouin G, Maurais G, Garzon S, Rivard ChR Degeneration of the human lumbar spine ligaments: an Degeneration of the human lumbar spine ligaments: an
ultrastructural study. Path Res Pract 1989;184:369-75.

13 Newman PH. Sprung back.J Bone Joint Surg (Br) 1952;34B:30-7.

14 Putz R, Reichelt A. Structural findings of the coracoacromial ligament in rotator cuff rupture, tendinosis calcarea and supraspinatus syndrome. Z Orthop 1990; 128(1):46-50.

15 King JB, Perry DJ, Mourad K, Kumar SJ. Lesions of the patellar ligament. J Bone Joint Surg (Br) 1990;72B:46-8.

16 Kamikozuru M, Yamawa I, Fujii K, Koyama T. Myelopathy caused by hypertrophy of posterior longi-
tudinal ligament-case report. Proc Second Annual Meeting of Spinal Surgery 1974;19.

17 Kurata A, Tokiwa K, Kitahara I, et al. Myelopathy caused by hypertrophy of the posterior longitudinal ligament (HPLL). Case report. No-Shinkei-Geka 1987;15(6): 651-5.

18 Tihansky DP. Unilateral hypertrophy of the cervical ligamentum flavum presenting as pseudotumour. $N Y$ ligamentum flavum presenting
State $J$ Med 1986;86(10):536-8

19 Miller JD, Al-Mefty O, Middleton III TH. Synovial cyst at the craniovertebral junction. Surg Neurol 1989;31:239-42. 20 Prete PE, Henbest M, Michalski JP, Porter RW. Intraspinal elastofibroma. A case report. Spine 1983;8(7):239-42.

21 Kleinman GM, Dagi TF, Poletti CE. Villonodular synovitis in the spinal canal. Case report. J Neurosurg 1980;52: 846-8.

22 Vinstein AL, Cockerill E. Involvement of the spine in gout. A case report. Radiology 1972;103:311-12.

23 Dirheimer Y, Bensimon C, Christmann D. Syndesmoodontoid joint and calcium pyrophosphate dihydrate deposition disease (CPPD). Neuroradiology 1983;25: 319-21.

24 Bradau GB, Ferszt R, Kendall BE. Cranial meningiomas. London: Springer-Verlag, 1990:100-11.

25 Moskovich R, Crockard HA. Myelopathy due to hypertrophic nonunion of the dens: case report. J Trauma trophic nonunion

26 Lansen TA, Kasoff SS, Tenner MS. Occipitocervical fusion for reduction of traumatic periodontoid hypertrophic for reduction of traumatic periodon 